\title{
New Carabus Linnaeus, 1758 from China and Vietnam and description of the male of Carabus (Pseudocoptolabrus) chort- enensis Cavazzuti, 2005 (Coleoptera Carabidae)
}

Ivan Rapuzzi

Via Cialla 47, 33040 Prepotto; Italy; e-mail: info@ronchidicialla.it

\begin{abstract}
Four new subspecies of genus Carabus Linnaeus, 1758 (Coleoptera Carabidae) belonging to subgenus Apotomopterus and one new Carabus subspecies belonging to subgenus Pseudocoptolabus are described and figured. Two of these are originally from the southeastern part of Sichuan province (China): Carabus (Apotomopterus) kassandra planielongatus n. ssp. and Carabus (Apotomopterus) benardi alterego n. ssp.; one from Hunan province (China): Carabus (Apotomopterus) cyanipennis atripennis n. ssp.; one from Northeast Yunnan province (China): Carabus (Pseudocoptolabrus) taliensis xerophilous n. ssp.; one from Ha Giang province (Vietnam): Carabus (Apotomopterus) tonkinensis hagiangensis n. ssp. Carabus (Pseudocoptolabrus) chortenensis Cavazzuti, 2005 is considered as a valid species after examination of a male specimen from its type locality; the male imago and aedeagus are described and figured for the first time. Carabus (Pseudocoptolabrus) chortenensis mosso Deuve et Mourzine, 2005 comb. nov.
\end{abstract}

KEY WORDS

Carabus; Apotomopterus; Pseudocoptolabrus; taxonomy; Sichuan; Hunan; Yunnan; Ha Giang; China; Vietnam.

Received 09.01.2020; accepted 02.03.2020; published online 26.03.2020

\section{INTRODUCTION}

I recently had the opportunity to examine a large series of carabid beetles collected in China (Sichuan, Yunnan and Hunan provinces) and from the Northernmost part of Vietnam. Among the studied specimens, I identified five new subspecies of genus Carabus Linnaeus, 1758 (Coleoptera Carabidae) clearly different from all the hitherto known subspecies of each species. Four new subspecies belonging to subgenus Apotomopterus Hope, 1838: Carabus (Apotomopterus) kassandra planielongatus n. ssp.; C. (Apotomopterus) benardi alterego n. ssp.; C. (Apotomopterus) cyanipennis atripennis n. ssp.; C. (Apotomopterus) tonkinensis hagiangensis $\mathrm{n}$. ssp.; and one new subspecies belonging to subgenus
Pseudocoptolabus Reitter, 1896: C. (Pseudocoptolabrus) taliensis xerophilous n. ssp. The study of one male of Carabus (Pseudocoptolabrus) chortenensis Cavazzuti, 2005 collected in its type locality gave me the opportunity to confirm its validity as a species.

\section{RESULTS}

\section{Systematics}

Carabus (Apotomopterus) kassandra planielongatus $\mathrm{n}$. ssp. - Fig. 1 - http://zoobank.org/ 67ab6c74-0790-4358-b34a-04558dfd1686

Examined material. Holotype female, China, 
Southeast Sichuan province, Leibo, $50 \mathrm{~km}$ South from Shanlinggangxiang, VI.2019, Wang legit. The holotype is temporarily housed at the author's collection in Cialla di Prepotto (Udine, Italy) waiting to be definitively deposited in a public Institution.

DESCRIPTION OF THE HOLOTYPE. Length including mandibles: $37 \mathrm{~mm}$, elytra width: $11.5 \mathrm{~mm}$. Upper surface black with a very faint violet luster on the edges of elytral. Ventral surface, legs, palpi and antennae totally black.

Head narrow and elongate, long neck, eyes prominent. Front quite flat and very faintly punctured, vertex and neck strongly wrinkled. Mandibles long with a very acuminate apex. Palpi thin and very long; preapical segment of the labial palps with three setae. Antennae long and very thin, extending the half of the elytra.

Pronotum strongly sinuated, moderately transverse (about 1.15 times as broad as long); flat disc; sides of pronotum fully margined, slightly bent upwards; hind angles very short but acuminate, strongly bent downwards; surface of pronotum strongly punctured-rugulose. Elytra of very elongated oval shape, slender; quite flat disc; shoulders very narrow; sculpture of perfect triploid homodyname type; intervals very convex; primary intervals forming chains of quite short segments interrupted by small foveae, secondary and tertiary interval uninterrupted; sculpture gradually more rough and irregular towards the apex of elytra; whole margins of elytra strongly margined and bent upwards; preapical indentation strong, forming a rounded tooth. Very long and thin legs.

ETyMology. The name refers to the unusually elongate and flat habitus of the subspecies.

Remarks. The new subspecies differs from $C$. (Apotomopterus) kassandra kassandra Kleinfeld 1999 because of the very thin antennae; the narrower and cordate shape of pronotum; the longer and flatter shape of elytra, the roughly and convex elytral sculpture especially in the apical third; the elytral sides fully margined and bent upwards from the shoulders to the preapical indentation; stronger preapical indentation of elytra.

\section{Carabus (Apotomopterus) benardi alterego} n. ssp. - Fig. 2 - http://zoobank.org/67f34005ec2d-4a05-b42b-1d583923ed6a
ExAmined Material. Holotype female, China, Southeast Sichuan province, Leibo, $50 \mathrm{~km}$ South from Shanlinggangxiang, VI.2019, Wang legit. The holotype is temporarily housed at the author's collection in Cialla di Prepotto (Udine, Italy) waiting to be definitively deposited in a public Institution. Paratype: 1 female, same data as holotype in Albert Rautenstrauch collection (Augsburg, Germany).

DESCRIPTION OF THE HOLOTYPE. Length including mandibles $38 \mathrm{~mm}$, maximum width of elytra: 12.8 $\mathrm{mm}$. Upper surface uniformly black, shiny. Ventral surface, legs, palpi, antennae, and mandibles black.

Head of medium size; head surface strongly punctured and very strongly wrinkled, front smooth. Eyes of hemispheric shape. Very long and thin palpi, penultimate segment of the labial palpi with three-setae. Long antennae protruding beyond the half of the elytra.

Pronotum sinuated, slightly transverse (1.22 times as broad as long); sides uniformly margined and very slightly bent upwards; hind angles very few protruding behind the base; surface of pronotum strongly and uniformly rougly punctured.

Elytra of elongate shape, maximally dilated at the apical third; very strong preapical indentation, preapical tooth very long and acuminate; shoulders narrow and rounded; quite flat profile. Sculpture of elytra perfect homodyname triploid type; intervals convex and very regular, not sinuated; primary intervals forming quite long links interrupted by foveae; secondary and tertiary forming uninterrupted costae. Legs exceptionally long.

ETymology. The name wants to emphasise the very strong morphological similitude with the syntopic species C. (Apotomopterus) kassandra planielongatus $\mathrm{n}$. ssp.

REMARKs. The new subspecies is closely related to $C$. (Apotomopterus) benardi briseis Rapuzzi, 2018 but: smaller and sinuate pronotum; body more elongate and somewhat flatter; elytral sculpture of homodyname type. It is interesting to note that the new subspecies is syntopic with $C$. (Apotomopterus) kassandra planielongatus $\mathrm{n}$. ssp., the two species are morphologically very similar (sister species), but easily distinguish by stronger preapical indentation of elytra in C. (Apotomopterus) benardi alterego $\mathrm{n}$. ssp.

VARIABILITY. The paratype has no substantial morphological differences with the holotype. 


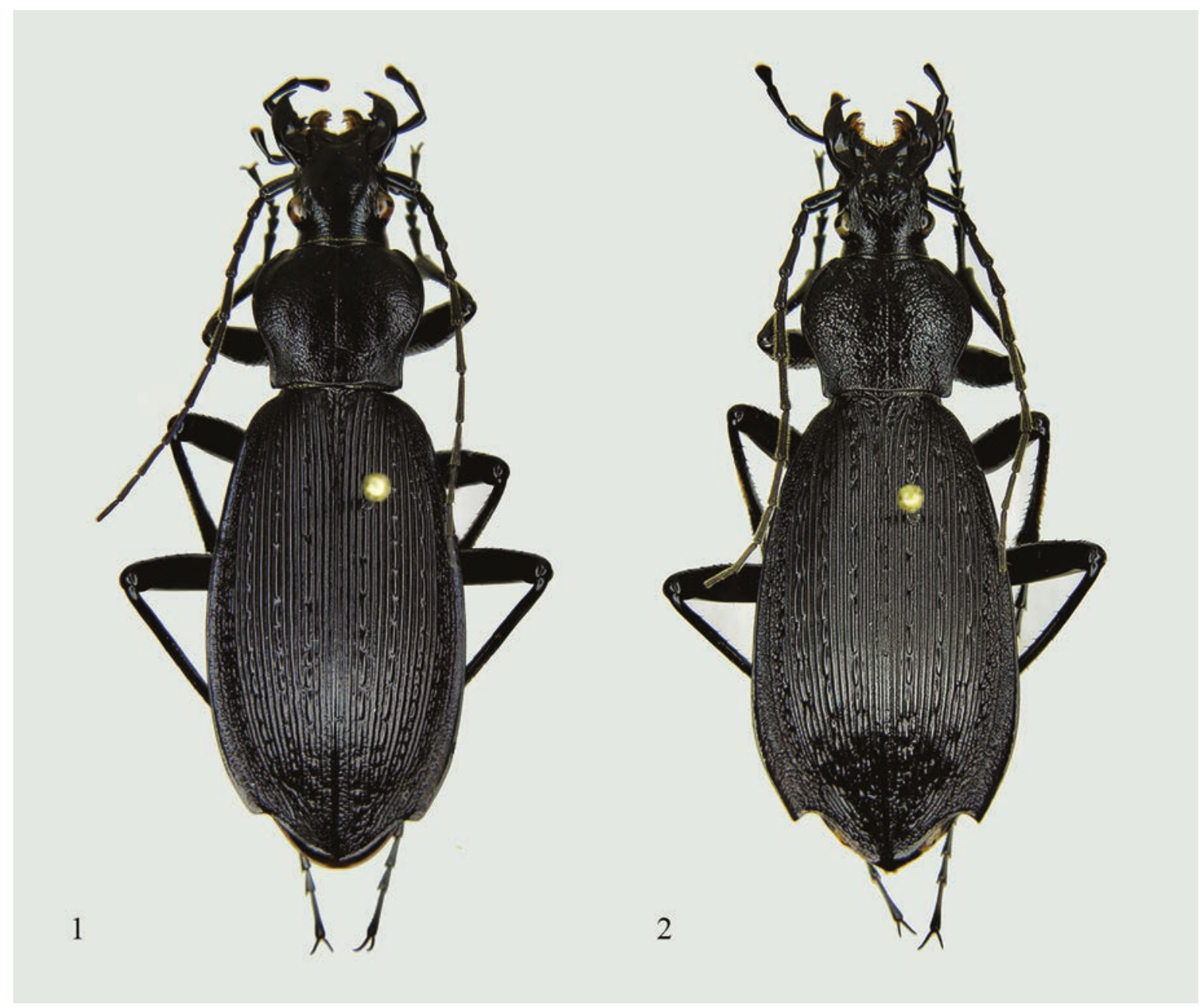

Figure 1. Carabus (Apotomopterus) kassandra planielongatus n. ssp., holotype.

Figure 2. Carabus (Apotomopterus) benardi alterego n. ssp., holotype.

Carabus (Apotomopterus) cyanipennis atripennis n. ssp. - Figs. 3-5 - http://zoobank.org/845a 5e85-5740-4782-84ef-7c94ac91600c

Examined material. Holotype male, China, Guangxi province, Yuecheng Ling, $1800 \mathrm{~m}$, 1/16.V.2008, V. Siniaev legit. The holotype is temporarily housed at the author's collection in Cialla di Prepotto (Udine, Italy) waiting to be definitively deposited in a public Institution. Paratypes: 4 males and 10 females, same data as holotype in the author's collection and in Albert Rautenstrauch collection (Augsburg, Germany).

DESCRIPTION OF THE HOLOTYPE. Length including mandibles $32 \mathrm{~mm}$, maximum width of elytra: $10 \mathrm{~mm}$. Colour uniformly slate black, shiny. Ventral side, legs, palpi, antennae, black; mandibles black with brownish base.

Head of medium size; very short neck; head surface faintly punctured and superficially wrinkled, front smooth. Eyes very big of hemispheric shape. Very long and thin palpi, penultimate segment of the labial palpi with three-setae. Very long antennae trespassing behind the half of the elytra.

Pronotum quite small and slightly transverse (1.12 times as broad as long), and slightly cordate; hind angles rounded, very few protruding behind the base and bent downwards; disc flat; surface of pronotum uniformly wrinkled.

Elytra very elongate; shoulders narrow and rounded; convex profile. Sculpture of elytra triploid homodyname type; all the intervals are convex; primary intervals forming short links interrupted by 
foveae; secondary and tertiary of the same size forming uninterrupted costae; punctured striae.

Male aedeagus typical of the species but: stronger with the apical portion of median lobe much shorter and larger in frontal view (Fig. 4); in lateral view (Fig. 5) the apex is stout and strongly curved on the left.

ETymology. The name wants to point out the unusual black colour without any blue-violet lustre.

VARIABILITY. The size ranges from 28 to 32 for the males and from 29 to 34 for females. Some specimens are black with a faintly cupper-brownish lustre. The elytra of females are larger and dilated with a very strong preapical indentation, preapical tooth very long and acuminate.

REMARKs. The new subspecies differs from $C$. (A.) cyanipennis cyanipennis Breuning, 1932 (including its subspecies) for the larger size, the color black without any blue-violet luster, the smaller and somewhat more cordate pronotum, the shape of male aedeagus and the stronger preapical indentation of the females. The elytral sculpture is stronger with intervals larger and more convex, the striae are punctured.

Carabus (Apotomopterus) tonkinensis hagiangensis $\mathrm{n}$. ssp. - Figs. 6-10 - http://zoobank. org/f5a6d29d-6c87-45e3-8f6b-09e6da00b1b9

EXAMINED MATERIAL. Holotype male, Vietnam, Ha Giang province, Lung Cu, 1600m, IV.2019, local collector leg. The holotype is temporarily housed at the author's collection in Cialla di Prepotto (Udine, Italy) waiting to be definitively deposited in a public Institution. Paratype: 2 females, same data as holotype in the author's collection and in Albert Rautenstrauch collection (Augsburg, Germany).

DESCRIPTION OF THE HOLOTYPE. Length including mandibles: $30.5 \mathrm{~mm}$, maximum width of elytra: 9 $\mathrm{mm}$. Dorsal side black, mat. Ventral side, legs, antennae and palpi black.

Head of medium size, quite long and strong; eyes big and convex; front nearly flat and smooth, vertex of the head very faintly and sparsely punctured, neck faintly wrinkled. Mandibles short and strong. Very long and thin palpi; preapical segment of the labial palps with three setae. Antennae very long and thin, extending over the half of the elytra.

Pronotum elongated, very slightly transverse (1.05 times as broad as long); cordate shape; hind angles of pronotum rounded, protruding behind its base; sides of pronotum fully margined and fully bent upwards; disc slightly convex; surface of pronotum uniformly wrinkled and punctured.

Elytra of oval elongated shape; disc quite convex; rounded shoulders; triploid eterodyname type of sculpture of elytra: primary intervals very convex, forming costae interrupted by large foveae only from the apical half of the elytra; secondary forming very wake costae with grains; tertiary forming range of grains. The male aedeagus is typical of the species but median lobe in general longer and stronger, strongly curved at the apex in frontal view (Figs. 7, 8).

Etymology. The new subspecies is named after the province of Ha Giang (Vietnam).

VARIABILITY. Very small variability: the size of females ranges from 30.5 to $32 \mathrm{~mm}$.

REMARKS. The new subspecies is morphologically closest to $C$. tonkinensis yenbaiensis Deuve, (2013) but: head proportionally larger; stronger mandibles; hind angles of pronotum larger and rounded, longer protruding behind the pronotal base; sides of pronotum stronger bent upwards especially in the apical part; sculpture of elytra characterized by secondary and tertiary intervals less convex; elytra of the female with stronger and more acuminate preapical indentation; median lobe of male aedeagus longer and stronger, strongly curved at the apex in frontal view (compare figure 7 and figure 8 with figure 9 and figure 10). The type locality of $C$. tonkinensis hangiangensis $\mathrm{n}$. ssp. is more on the East and it is separate from $C$. tonkinensis tonkinensis Deuve (1990) (including imurai Gottwald, 1991) and C. tonkinensis yenbaiensis by the plane of the Red River Valley (Sōng Hóng River).

Carabus (Pseudocoptolabrus) taliensis xerophilous $\mathrm{n}$. ssp. - Fig. 11 - http://zoobank. org/2d 45b4f4-a47a-45d3-90b5-ba6e3ab0d980

EXAMINED MATERIAL. Holotype female, NE Yunnan, Dahai Xiang, VII.2019, Wang legit. The holo- 


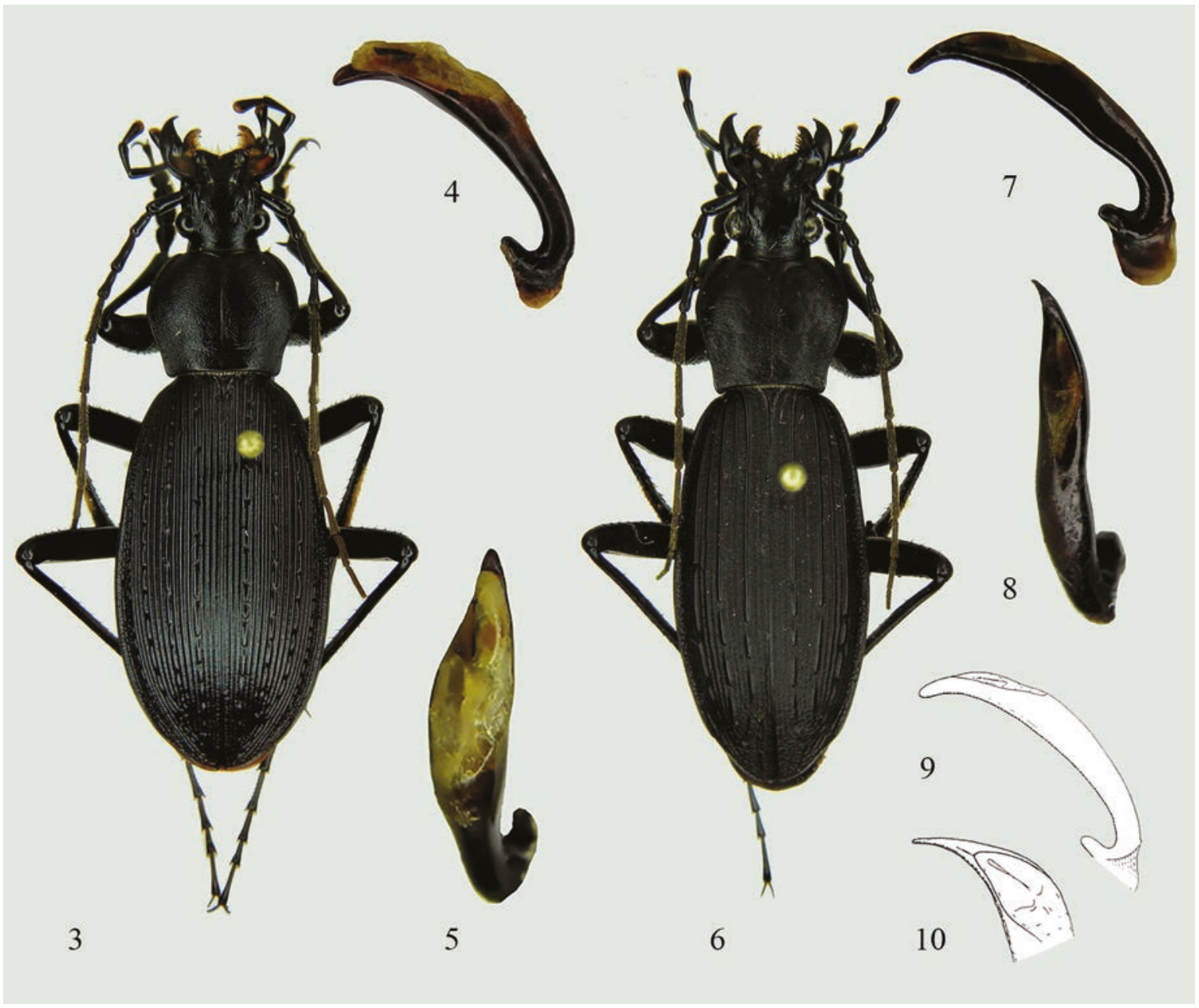

Figures 3-5. Carabus (Apotomopterus) cyanipennis atripennis n. ssp. Fig. 3: holotype. Fig. 4: paratype male, aedeagus in lateral view. Fig. 5: paratype male, aedeagus in dorsal view. Figures 6-8. Carabus (Apotomopterus) tonkinensis hagiangensis n. ssp. Fig. 6: holotype. Fig. 7: paratype male, aedeagus in lateral view. Fig. 8: paratype male, aedeagus in dorsal view. Figures 9, 10. Carabus (Apotomopterus) tonkinensis yenbaiensis Deuve, 2013. Fig. 9: male aedeagus in lateral view, original draw by Deuve, 2013. Fig. 10: idem, male aedeagus in dorsal view, original draw by Deuve, 2013.

type is temporarily housed at the author's collection in Cialla di Prepotto (Udine, Italy) waiting to be definitively deposited in a public Institution.

DESCRIPTION OF THE HOLOTYPE. Length including mandibles: $34.5 \mathrm{~mm}$, maximum width of elytra: 11 $\mathrm{mm}$. Dorsal side totally black without any metallic lustre, mat. Ventral side, legs, antennae and palpi black. Thickened head, neck nearly large as the base of pronotum; small eyes, moderately prominent; head surface punctured and faintly rugulose only over the supraocular sulcus. Mandibles long and strong, regularly curved. Long palpi; apical segment of maxillary and labial palpi dilated; sub api- cal segment of labial palpi multi setose. Antennae short, very thin, extending the pronotal base with 5 articles.

Narrow pronotum ( 0.95 times as broad as long), slightly sinuated; hind angles of pronotum very few protruding behind the base, strongly bent downwards; surface of pronotum uniformly granulose.

Oval shape of elytra, elytral disc very convex; shoulders salient. Elytral sculpture triploid eterodyname type, strongly irregular but moderately roughly among the other $C$. (Pseudocoptolabrus) taliensis Fairmaire, 1886 forms; the primary tubercles are distinct but not very convex, separated by 
rounded and quite deep foveae; secondary and tertiary intervals are indistinct fused in a single intermediate zone of grains.

Legs short and quite strong for the species.

Etymology. The name wants to emphasise the dry environment of the type locality where the new subspecies lives.

Remarks. Carabus (Pseudocoptolabrus) taliensis is a montane species inhabiting high altitude forests of the alpine zone with a clear preference for cold and wet places. The species is widespread in southwestern China where forming isolated populations, as a result about 30 different subspecies are known (Imura, 2018). Carabus (Pseudocoptolabrus) taliensis xerophilous $\mathrm{n}$. ssp. seems to be endemic on the Dahai Mountains and it is one of the South-easternmost population of the species, despite the usual occurrence of the species in wet places the new subspecies inhabits dry stony meadows with tall grass, where it seems to be very rare.

Morphologically, the new subspecies is close to Carabus taliensis jiaozicola Deuve (2019) but: wider and thickened shape, shorter hind angles of pronotum, stronger and roughly elytral sculpture. Geographically, the new subspecies lives more on the East on a peripheral mountain range separated by the deep valley of Xiao Jang River.

Carabus (Pseudocoptolabrus) chortenensis Cavazzuti, 2005 bona species (Fig. 12-14)

Carabus (Pseudocoptolabrus) firmatus subsp. chortenensis Cavazzuti, 2005

Description of THE Male of $C$. (Pseudocoptolabrus) chortenensis. Length including mandibles $34.5 \mathrm{~mm}$, maximum width of elytra: $10.5 \mathrm{~mm}$. Colour: head and pronotum black with quite intense blue-violet lustre; elytra uniformly black, shiny; ventral side, legs, palpi, antennae, and mandibles black.

Head elongate, moderately ticked; surface faintly punctured and superficially wrinkled, frons smoother. Mandibles very long and narrow, evenly curved. Long and quite thin palpi; apical segment of maxillary and labial palpi dilated; sub apical segment of labial palpi with three-four setae. Antennae very long and thin, extending to the half of elytra.
Pronotum elongated, not transverse (as broad as long), strongly cordate with the maximum wide at the anterior third and very narrowed before the base; hind angles strongly divergent and slightly prominent; upper surface of pronotum uniformly punctured.

Elytra very elongate but strong and very convex; shoulders narrow and rounded. Very strong sculpture of elytra: primary tubercles very convex, irregularly interrupted by deep foveae, secondary and tertiary forming grains very convex and irregularly disposed between the primary intervals.

Legs very long but quite strong. The 4th protarsal segment not dilated, without adhesive sole.

Male aedeagus in lateral view (Fig. 13) and in dorsal view (Fig. 14)

Remarks. Cavazzuti (2005) described on the basis of a single female specimen the taxon "chortenensis" as a subspecies of $C$. (Pseudocoptolabrus) firmatus Cavazzuti (1997). Subsequentially, $C$. chortenensis was considered as a subspecies of $C$. taliensis by Deuve (2013a) and Imura (2018). Recently, I had the opportunity to study a male specimen of "chortenensis" collected in its type locality. (see above) and I propose to consider "chortenensis" as a different species separated from C. firmatus and Carabus taliensis (Fairmaire, 1886).

Carabus chortenensis is syntopic with C. taliensis stupaensis Cavazzuti, 1996 and easily distinguished from it by the various strong characters already highlighted by Cavazzuti (2005). Morphologically, C. chortenensis is close with C. firmatus but it is different because of: head larger with a smoother sculpture (faintly punctured in chortenensis while it is strong wrinkled in firmatus); pronotum larger, strongly cordate, surface slightly punctured and not wrinkled; elytra stronger and more convex, sculpture strongly irregular; shorter and stronger legs, protarsal segments strongly dilated; different shape of male aedeagus (in general larger and stronger, the apex is of tooth shape in chortenensis and of spatula shape in firmatus). For all the above mentioned characters I propose to consider $C$. chortenensis as a separate valid species.

Few months after the description of C. (Pseudocoptolabrus) firmatus subsp. chortenensis (Cavazzuti, 2005), Deuve \& Mourzine (2005) described Carabus (Pseudocoptolabrus) taliensis mosso 


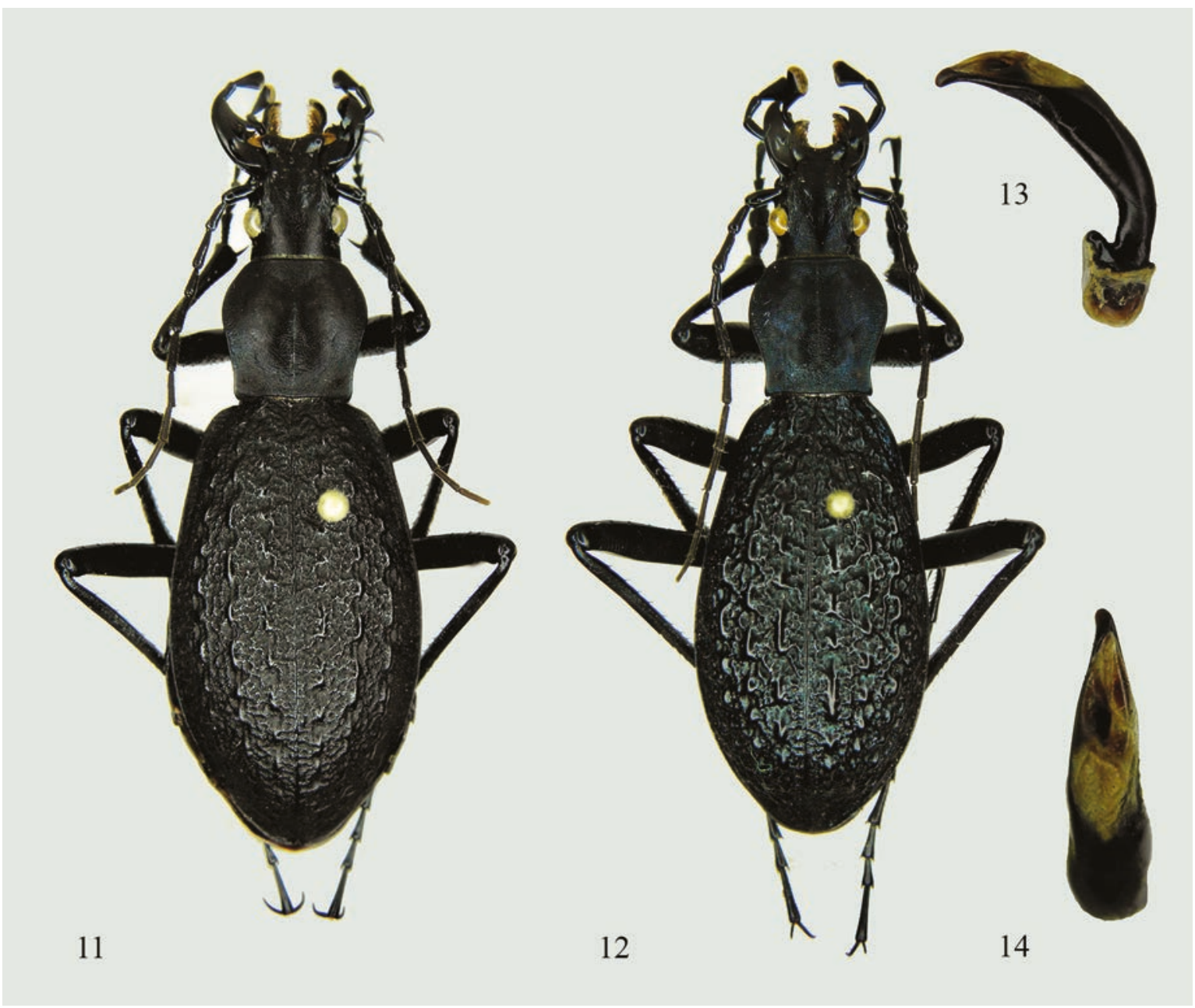

Figure 11. Carabus (Pseudocoptolabrus) taliensis xerophilous n. ssp., holotype. Figures 12-14. Carabus (Pseudocoptolabrus) chortenensis Cavazzuti, 2005. Fig. 12: male. Fig. 13: aedeagus in lateral view. Fig. 14: aedeagus in dorsal view.

which is morphologically and geographically closely related with $C$. chortenensis as highlighted by the Author in the original paper. For this taxon I propose the following new combination: Carabus (Pseudocoptolabrus) chortenensis mosso Deuve et Mourzine, 2005 comb. nov.

\section{ACKNOWLEDGEMENTS}

I wish to thank my friend and colleague Ing. Albert Rautenstrauch from Augsburg (Germany) for his kindness to provide me with a significant part of the material fundamental for the present study and Dr. Yoshiyuki Naghata (Japan) for his help with literature.

\section{REFERENCES}

Cavazzuti P., 1997. Descrizione di nuovi Cychrus e Carabus L. delle provincie di Sichuan, Yunnan e Guizhou, Cina meridionale (Col., Carabidae). Coléoptères, 2: 47-76.

Cavazzuti P., 2005. Nuove sottospecie di Carabus della Cina (Coleoptera, Carabidae). Lambillionea, 105: 457-461

Deuve T., 1990. Description de deux nouveaux Carabus d'Extrême-Orient. Bulletin de la Société Sciences Nat, 65: 26-28

Deuve T., 2013. Deux nouveaux Carabus L., 1758, du Vietnam et du Sichuan (Coleoptera, Carabidae). Coléoptères, 19: 151-157

Deuve T., 2013a. Cychrus, Calosoma et Carabus de Chine. Pensoft Sofia-Moscow, 286 pp., 137 figures. 
Deuve T., 2019. Nouveaux Carabus de Chine et d'Asie centrale (Col., Carabidae). Coléoptères, 25: 135-144.

Deuve T. \& Mourzine S., 2005. Trois nouveaux Pseudocoptolabrus des régions limitrophes du Yunnan et du Sichuan (Coleoptera, Carabidae). Coléoptères, 11: 205-211.

Gottwald J., 1991. Zwei neue ostpaläarktische Carabus-
Taxone (Coleoptera, Carabidae). Entomologica basiliensia, 14: 23-26.

Imura Y., 2018. Contribution to the knowledge of carabid beetles (Coleoptera, Carabidae) from China (6): A new species of the subgenus Pseudocoptolabrus of the genus Carabus discovered from Southwest Yunnan. Elytra, Tokyo, 53: 29-34 